\title{
Establishing a Radiation Safety Credential for Nuclear Medicine Technologists
}

\author{
Frederic Fahey ${ }^{1,2}$, Briana Sexton-Stallone ${ }^{1}$, and Jon Shepard ${ }^{3}$ \\ ${ }^{1}$ Boston Children's Hospital, Boston, Massachusetts; ${ }^{2}$ Harvard Medical School, Boston, Massachusetts; and ${ }^{3}$ Fusion Physics, LLC, \\ Valrico, Florida
}

\begin{abstract}
Several nuclear medicine technologists (NMTs) have specific responsibilities and considerable experience in radiation safety. In many instances, the technologist's level of knowledge regarding radiation safety goes beyond what is typically expected. The Nuclear Medicine Technology Certification Board performed a needs assessment for a radiation safety credential for NMTs. The assessment included the delivery and evaluation of 2 surveys, which both indicated that there was interest among NMTs for a specific credential regarding radiation safety. Based on this information, the Nuclear Medicine Technology Certification Board decided to move forward on the development of a content outline and an examination in this regard. The board also developed eligibility criteria for those interested in taking the examination. The first administration of the examination occurred in November 2017. This article describes in detail the needs assessment performed before the decision to develop the credential, as well as the process followed to generate the examination and an analysis of the results of its first administration.
\end{abstract}

Key Words: certification; professional development; radiation safety

J Nucl Med Technol 2018; 46:391-393

DOI: 10.2967/jnmt.118.214395

\section{$\mathbf{T}$} he Nuclear Medicine Technology Certification Board (NMTCB) has recently introduced a radiation safety credential specifically for nuclear medicine technologists (NMTs). In 2015, a public survey was distributed by the NMTCB via email to active NMTs to determine their interest in a potential radiation safety credential to be offered by the NMTCB. The survey stressed that this proposed credential would not be recognized by the Nuclear Regulatory Commission as a Specialty Board for Radiation Safety Officer (RSO) but rather would display that an individual has obtained significant knowledge regarding radiation safety, regulatory issues, and emergency procedures

\footnotetext{
Received May 8, 2018; revision accepted Jul. 9, 2018.

For correspondence or reprints contact: Frederic Fahey, Division of Nuclear Medicine and Molecular Imaging, Boston Children's Hospital, 300 Longwood Ave., Boston, MA 02115.

E-mail: frederic.fahey@childrens.harvard.edu

Published online Aug. 3, 2018

COPYRIGHT (c) 2018 by the Society of Nuclear Medicine and Molecular Imaging.
}

within a medical use license. A total of 3,094 NMTs responded to the survey, with $79 \%$ of the respondents answering that they would be interested in pursuing a radiation safety credential (Table 1). The following article reviews the process by which the NMTCB developed and delivered the examination. We also report on the implementation and results of the inaugural administration of the examination.

\section{TASK ANALYSIS}

Given such interest, NMTCB developed and conducted an RSO Task Survey to determine the variety and frequency of radiation safety tasks being performed by RSOs, as well as by NMTs who may or may not be RSOs. Physicians, physicists, and technologists responded to the survey. The intent of the survey was to see what RSO responsibilities were delegated to the NMT on a daily, weekly, and monthly basis. The survey respondents were asked to indicate how often they perform tasks related to the following: radiation instrumentation; radiation measurement and dosimetry; personnel monitoring; radiation protection; the shipping, receiving, and disposal of radioactive materials; administrative controls and reporting; emergency procedures; radionuclide therapy and managing therapy patients; brachytherapy; fetal dose calculations; CT safety issues; X-ray safety issues; fluoroscopy safety issues; and MRI safety issues, as well as the time spent assisting with staff education and organizationwide radiation safety oversight. From this survey, NMTCB learned that many of the safety and regulatory matters regarding the radioactive materials license, x-ray and fluoroscopy, CT, and MR departments often fall within the RSO's scope of responsibility.

Of the 67 individuals that received it, a total of 31 individuals completed the survey. The results of this survey indicated exactly which personnel are responsible for the radiation safety tasks routinely performed in institutions on a daily basis (Table 1). As indicated by the survey results, it was evident that many NMTs are not used in the position of the RSO for their facility. However, the survey results also indicated that even if the NMT is not the RSO at a facility, it is frequently the NMT who has been delegated to perform many duties on behalf of the RSO. When respondents were asked whether the survey had failed to include any related safety tasks or responsibilities within the scope of the survey questions, a very 
TABLE 1

Needs Assessment Survey Results

\begin{tabular}{|c|c|}
\hline Question & Response \\
\hline \multicolumn{2}{|l|}{$\begin{array}{l}\text { Would you be interested obtaining } \\
\text { an RSO credential from the NMTCB to } \\
\text { attest to your knowledge of radiation } \\
\text { safety matters? }\end{array}$} \\
\hline $\begin{array}{l}\text { Yes, I would be interested in pursuing } \\
\text { an RSO credential }\end{array}$ & $79 \%$ \\
\hline $\begin{array}{l}\text { No, I have no interest in an RSO } \\
\text { credential }\end{array}$ & $18 \%$ \\
\hline No answer & $4 \%$ \\
\hline Not completed & $0 \%$ \\
\hline \multicolumn{2}{|l|}{$\begin{array}{l}\text { Are you currently employed in the } \\
\text { position of RSO at your facility, } \\
\text { hospital, or institution? }\end{array}$} \\
\hline Yes, I am the RSO & $9 \%$ \\
\hline No, someone else is the RSO & $70 \%$ \\
\hline $\begin{array}{l}\text { I am not currently the RSO, but I } \\
\text { perform the duties of an RSO }\end{array}$ & $8 \%$ \\
\hline $\begin{array}{l}\text { I am currently in the position of an } \\
\text { assistant RSO or associate RSO }\end{array}$ & $4 \%$ \\
\hline $\begin{array}{l}\text { My employer does not have someone } \\
\text { in the RSO position }\end{array}$ & $5 \%$ \\
\hline No answer & $0 \%$ \\
\hline Not completed & $4 \%$ \\
\hline
\end{tabular}

few respondents indicated that laser safety fell under their scope of responsibilities. It was also determined that NMTs are not typically asked to assist with laser safety.

Once the survey data were analyzed, the NMTCB Board of Directors agreed to endorse the plan to move forward with developing a new radiation safety credential specifically designed for NMTs. Using the data provided from the RSO Task Survey, the Board determined that the certification examination should be designed to assess whether an NMT has a reasonable level of expert knowledge in radiation safety regarding radioactive materials and CT, as well as a basic understanding of and competency in the safety and regulatory matters in other areas within radiology such as MR, fluoroscopy, and x-ray safety. The NMTCB agreed that such a credential would be a valuable asset to the field of nuclear medicine and a resource for safety of medical imaging in general. An NMT who has demonstrated significant understanding regarding radiation safety should be able to help ensure that facilities are properly and continually compliant with their radioactive material licensing requirements. The credential should also help supervisors and RSOs identify NMTs who have demonstrated their knowledge in radiation safety and related issues.

\section{TARGET AUDIENCE}

At many facilities the NMT is considered the expert in the safe handling of radioactive materials. This is reasonable, as the NMT is the most highly trained individual in the day-to-day handling of radioactive materials. In smaller practices such as outpatient nuclear cardiology clinics, the RSO may be a physician who relies on the NMT for administering the radiation safety program. Larger facilities are typically required to have a Radiation Safety Committee as well as an RSO as part of the radioactive materials license; however, the program may still be managed on a daily basis by an NMT. In addition, the Radiation Safety Committee frequently deals with safety issues beyond the scope of radioactive materials, including fluoroscopy, CT, and MR safety. Therefore, it was decided that the radiation safety certification should be designed to elevate the practice of the NMT in this regard. The typical applicant for the radiation safety certification is expected to be the NMT who is actively working in personnel-related radiation safety as well as having some routine interactions in all areas of radiology safety.

\section{EXAMINATION DEVELOPMENT}

Based on this evaluation, the NMTCB has developed and delivered a radiation safety certification examination specifically for NMTs who wish to lend credibility to their knowledge and experience in radiation safety (1). Technologists who pass the certification examination will be noted as NMTCB(RS). This certification is particularly aimed at those who work closely with the RSOs at their institution or plan to pursue a position as an RSO. The plan to develop the radiation safety examination was approved by the NMTCB in spring 2016, and this plan was implemented over the following $18 \mathrm{mo}$. In fall of 2016, a team of content experts including several members of the NMTCB came together to finalize the content outline for the credential and begin writing items for the examination. It was decided to develop the examination across 6 content areas: radioactive materials, fluoroscopy, CT safety, MR safety, radiobiology, and radiation dose optimization. The NMTCB felt it was important to include topics such as MR safety, fluoroscopy, and radiography as it is essential for someone involved in radiation safety to have a well-rounded understanding of the safety of medical imaging as a whole. As discussed above, the needs assessment indicated that NMTs are not typically involved in laser safety, and thus, it was decided not to include laser safety within the radiation safety examination. A more advanced level of understanding was expected for the sections regarding radioactive materials and CT, as these topics are more relevant to day-to-day operations in nuclear medicine. The other topics were tested at a more basic level. Over the next 6 mo, 300 items were generated across all content areas. A $\beta$-examination including all 300 items was administered by the NMTCB to 17 people at the 2017 SNMMI Annual Meeting in June. Based on the results of the $\beta$-examination, a version of the examination with 200 items was finalized.

The radiation safety certification exam was administered by the NMTCB for the first time on November 3, 2017.

The examination was intended to have a reasonable level of both difficulty and breadth across all content areas of radiation safety. The final content of the examination comprised 50\% radioactive materials, $15 \%$ fluoroscopy, 


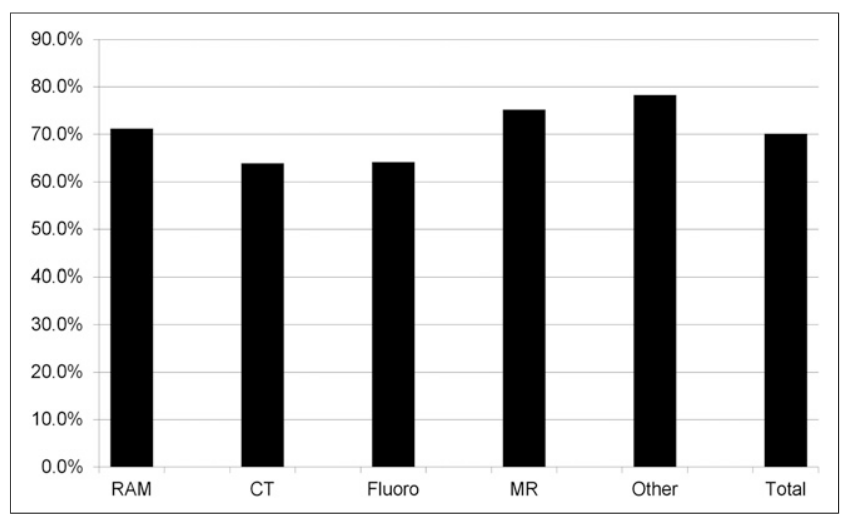

FIGURE 1. Percentage of correct responses by content area. Figure shows that across 6 content areas, examinees demonstrated similar performance ranging from $63.9 \%-78.3 \%$ (1). RAM = radioactive material; $\mathrm{CT}=$ computed tomography; Fluoro $=$ fluoroscopy; MR = magnetic resonance.

$15 \%$ CT safety, $10 \%$ MR safety, and $10 \%$ other topics as described above. Of the 68 technologists who took the first examination, $55(81 \%)$ passed. Most examination takers demonstrated knowledge across all content areas (Fig. 1). The board was very pleased with the results of the first examination as they showed that the examination was not too easy, too difficult, or too focused in a certain area, which is always a concern when administering a new examination. Because the first certifications were issued within the last year, it is too early to determine the professional impact it has had on the careers of those with the credential. The NMTCB plans to follow up with these early diplomates in a few years.

\section{CONCLUSION}

Based on survey results, the NMTCB determined that there was a clear need for a radiation safety certification specifically for NMTs with significant knowledge in this arena. The NMTCB decided that it was essential that the examination associated with this certification cover other topics beyond radioactive materials, such as CT, fluoroscopy, and MR safety. The examination, which was developed over $18 \mathrm{mo}$, was successfully delivered by the NMTCB in November 2017. The NMTCB offered the examination a second time in August 2018. Dates of future examinations are yet to be determined.

Individuals interested in additional information regarding the RS certification can visit the NMTCB website (https:// www.nmtcb.org/specialty/radiation-safety-certification-exam. php) or contact NMTCB directly.

\section{DISCLOSURE}

No potential conflict of interest relevant to this article was reported.

\section{REFERENCE}

1. Fahey FH. NMTCB's newest certification program: the Radiation Safety Credential. MailChimp website. https://mailchi.mp/527074e7flea/ullm1qmig5-701781. Published Winter 2018. 